\title{
Evaluating the level of professional moral courage of pre-hospital emergency staff in the management of patients with COVID-19
}

\author{
FATEMEH ALIAKBARI ${ }^{1, \mathrm{c}, \mathrm{E}, \mathrm{F}}$, MOHAMMAD HEIDARI ${ }^{1, \mathrm{~A}, \mathrm{~B}, \mathrm{D}, \mathrm{E}, \mathrm{G}}$, SADEGH HEYDARPOOR ${ }^{2, \mathrm{~B}, \mathrm{c}}$, \\ ORCID ID: 0000-0002-4416-9786 ORCID ID: 0000-0001-7767-5645 \\ SALMAN YADOLLAHI ${ }^{3, \text { B, C }, \text { RAHIM ALI SHEIKHI }}$, B, D \\ ORCID ID: 0000-0002-6191-5744 \\ ${ }^{1}$ Community-Oriented Nursing Midwifery Research Center, Shahrekord University of Medical Sciences, \\ Shahrekord, Iran \\ ${ }^{2}$ Disaster and Emergency Medical Management Center, Shahrekord University of Medical Sciences, Shahrekord, \\ Iran \\ ${ }^{3}$ Disaster and Emergency Medical Management Center, Shahrekord University of Medical Sciences, Shahrekord, \\ Iran
}

A - Study Design, B - Data Collection, C - Statistical Analysis, D - Data Interpretation, E - Manuscript Preparation, F - Literature Search, G - Funds Collection

Summary Background. Emergency Medical Services (EMS) are an important part of the healthcare system. Decision making is the most important part of their profession, as they often have to make a quick decision and act upon it, despite the critical conditions of the patient. They are often the first to deal with COVID-19, and they experience severe physical, mental or moral stress.

Objectives. The aim of this study was to determine the level of Professional Moral Courage (PMC) of Pre-Hospital Emergency (PHE) staff in the management of patients with COVID-19.

Material and methods. This descriptive, analytical study was conducted in 2020. A total of 200 PHE staff entered the study, recruited by the census sampling method. Data collection was undertaken using a validated moral courage questionnaire. The data was analyzed using SPSS version/21 with descriptive and analytic tests.

Results. The mean age of the participants was $34.42 \pm 7.14$, and mean of their work experience was $10.29 \pm 6.59$ years, of the mean moral courage score was $90.77 \pm 2.97$. There was a significant relationship between the mean score of moral courage and age, type of employment and participation in disaster exercises and training courses $(p<0.001)$.

Conclusions. The findings of the study showed a significant relationship between various variables and level of moral courage in PHE staff. Awareness of the moral courage of PHE staff is the first step to improve their preparedness. This study provides evidence of the need and potential positive impact of moral education opportunities for healthcare team.

Key words: COVID-19, courage, emergency medical services.

Aliakbari F, Heidari M, Heydarpoor S, Yadollahi S, Sheikhi RA. Evaluating the level of professional moral courage of pre-hospital emergency staff in the management of patients with COVID-19. Fam Med Prim Care Rev 2021; 23(4): 406-411, doi: https://doi.org/10.5114/ fmpcr.2021.110352.

\section{Background}

Events and disasters are important public health and community health problems around the world. In order to protect the health of people in such cases, several organizations have been established, each of which fulfills this important task by taking on responsibilities. Among these, we can mention PHE staff, which plays a role in providing medical services at the patient's bedside in emergency cases [1]. PHE staff often face chronic stressors, such as injury, patient unconsciousness or even death, which, in many cases, often lead to physical and psychological stress for them [2,3]. PHE staff are graduates of medical sciences universities who have been trained to work in critical situations and are usually the first to deal with critical patients (first responder) [4]. PHE staff are an important part of the healthcare system, and emergency care, especially pre-hospital care, is one of the most important pillars of medical care. In fact, the most important component of the pre-hospital emergency system is efficient and operational manpower to deal with all kinds of events and diseases. EMS are the most sensitive part of the medical profession, because often, with proper and timely care, the patient can be saved from certain death or disability, while negligence and any wrong action may cause irreparable damage [5]. Today, in the field of health care, these employees are widely faced with complex issues and problems due to the abundance of disasters, technological advances and ethical and cultural factors that bring them various stresses $[6,7]$. On the other hand, decision making is the most important and, at the same time, the riskiest part of their profession, because these people often have to make a decision and act quickly in spite of patient with critical conditions [7]. Therefore, the ability to make decisions in all practical and ethical situations [8], and the application of useful strategies to develop this skill for emergency medical staff, is essential [9]. Proper triage is also one of the examples of complex decisions that include patient consideration and other factors of the medical system, which is one of the most important features of this profession, and sometimes creates moral challenges for them [10]. Much of the decision making of PHE staff has to do with moral challenges, for exam- 
ple: How to transport patients to the emergency care facility? What is the basis for prioritizing who gets services faster? How can provide equal access to emergency medical services? [11].

On the other hand, part of the problem for PHE staff is the moral distress that is introduced as follows: a situation in which we know the right moral work, but organizational or social constraints make it almost impossible to do the right thing. This situation threatens central values and moral integrity, and PMC is needed to get through them properly [12]. PMC is one of the most important strategies proposed by ethics experts to deal with the negative effects of moral stress and support PHE staff when making decisions [13]. Exercising PMC helps the employees of the care delivery system to provide high quality care, prevents frequent changes of place of work and resignation from a job and also leads to job satisfaction [14].

The 2019 coronavirus disease (COVID-19), which has been prevalent in Wuhan, China, since late 2019, is a frightening and highly contagious disease $[11,15]$. The spread of this virus has become a disaster in many parts of the world, including Iran, and has caused PHE staff to be severely deficient both in labor force $[16,17]$ and Personal Protection Equipment (PPE) $[18,19]$. The World Health Organization (WHO) has designated it as a global emergency situation, which brings a lot of stress to all components and staff of the healthcare delivery system [13]. COVID-19 is highly contagious, thus any contact with infected patients can lead to the transmission of the virus and the spread of the disease; therefore, healthcare providers, during transmission or contact, care and treatment staff in different parts of the hospital and PHE staff may become easily infected $[20,21]$. The highly contagious nature of the virus infects most sections of society, including PHE staff who are in direct contact with these patients, and no one can guarantee that COVID-19 has not played a role in its spread [22]. In these cases, we are faced with moral challenges like observing confidentiality in cases of affliction, observing justice and tasking responsibility towards ourselves and others that make decision making difficult [13]. PHE staff are often the first to deal with COVID-19 and experience severe physical, mental or moral stress. Like other people, they may have doubts about their abilities or priorities, and sometimes they may be overwhelmed by fear of illness and may find themselves in a situation where they prefer individual interests to collective interests and are unable to make the right decisions. They also need PMC to survive the stress and tension caused by a global disaster like the COVID-19 pandemic, as well as to strengthen their decision-making power, but according to reviews, no study has been conducted to examine this issue.

\section{Objectives}

Accordingly, considering the importance of PMC to provide care during the COVID-19 pandemic, this study was conducted to determine the level of PMC of PHE staff in the management of patients with COVID-19.

\section{Material and methods}

\section{Study design}

This is a descriptive, cross-sectional study that was conducted in the second half of 2020 with the aim of assessing PMC and the factors affecting it in the PHE staff of Chaharmahal and Bakhtiari Province in the face of COVID-19. Data was gathered by the available sampling method, and the inclusion criteria included willingness to participate in the study, having at least one year of operational experience in emergency medical bases and active presence from the beginning of the outbreak of COVID-19 to the time of the study.

\section{Ethical approval}

The present study was approved by Ethics Committee of the Medical Sciences University of Shahrekord (Ethics code: IR.SKUMS.REC.1399.042). After explaining the objectives of the study and gaining satisfaction with the samples participating in the study, questionnaires were given to the participants, and they were asked to answer the questions. Written informed consent was obtained from all participants, and they were assured that their provided information would remain confidential.

\section{Data gathering}

The researcher assured the individuals that participation in the study was completely optional and that their information would remain confidential and anonymous. In order to collect data, a questionnaire including two sections of demographic information and the standard questionnaire of PMC, which was developed in 2009 by Sekerka et al. [23], was used. This questionnaire has five dimensions, and each dimension has three items: 1 . Moral agency: Willingness to do and having a strong will to perform moral behavior; 2 . Multiple values: Ability to use multiple values in moral decision making and adherence to beliefs despite external desires or demands; 3 . Endurance of threats: Accepting moral issues in spite of real or imagined dangers or threats; 4 . Going beyond compliance: One not only pays attention to the rules and their purpose, but also goes beyond obedience to the rules to do the right and appropriate thing; 5 . Moral goal: To be motivated to perform tasks that require decisions. Each answer was scored 1 to 7 on a 7-point scale from "never true" to "always true". The range of items scores in each dimension varies from minimum 3 to maximum 21, and the total score is at least 15 and at most 105 [23]. Validity and reliability of the Persian version of this questionnaire were carried out by Khoshoei in 2016 and was reported as desirable [24]. The reliability of the data collecting tools in this study was determined by Cronbach's alpha to be 0.89 , which shows it meets the desired reliability.

\section{Data analysis}

The data was analyzed using SPSS version/21 with descriptive statistics (mean and standard deviation for quantitative and chi-square data, frequency and percentage for qualitative data) and analytic tests. The level of significance for all tests was considered to be 0.05 .

\section{Results}

We studied PMC and the factors affecting it in the PHE staff of Chaharmahal and Bakhtiari Province in the face of COVID-19. The age of the participants was in the range of 22 to 66 years (34.42 \pm 7.14 ), and the mean and standard deviation of their work experience was $10.29 \pm 6.59$ years. Among 200 PHE staff participating in this study, 134 were married (67\%), 124 had a bachelor's degree (62\%), 125 had no disaster-related in-service training experience (62.5\%), 148 had participated in the maneuver experience (74\%), and 123 had attended the disaster experience (61.5\%). The demographic characteristics are presented in Table 1.

The mean and standard deviation of PMC of PHE staff was $90.77 \pm 2.97$. The mean of the moral courage score in different domains is presented in Table 2 .

The results of the independent $t$-Test showed that the mean score of PMC was significantly higher in the PHE staff with the disaster-related in training experience than in those who had no training experience $(p<0.05)$. 


\begin{tabular}{|c|c|c|c|}
\hline \multicolumn{2}{|l|}{ Parameters } & \multirow{2}{*}{$\frac{n}{66}$} & \multirow{2}{*}{\begin{tabular}{|l|}
$\%$ \\
33 \\
\end{tabular}} \\
\hline Marital status & single & & \\
\hline & married & 134 & 67 \\
\hline \multirow[t]{4}{*}{ Level of education } & diploma & 11 & 5.5 \\
\hline & associate degree & 56 & 28 \\
\hline & bachelor's degree & 124 & 62 \\
\hline & $\begin{array}{l}\text { master's degree and } \\
\text { higher }\end{array}$ & 9 & 4.5 \\
\hline \multirow[t]{2}{*}{ Workplace } & $\begin{array}{l}\text { urban emergency } \\
\text { care unit }\end{array}$ & 91 & 45.5 \\
\hline & $\begin{array}{l}\text { road emergency care } \\
\text { unit }\end{array}$ & 109 & 54.5 \\
\hline \multirow{2}{*}{$\begin{array}{l}\text { Experience in par- } \\
\text { ticipating in training } \\
\text { courses related to } \\
\text { disaster management }\end{array}$} & yes & 75 & 37.5 \\
\hline & no & 125 & 62.5 \\
\hline \multirow{2}{*}{$\begin{array}{l}\text { History of participat- } \\
\text { ing in exercises or } \\
\text { drills }\end{array}$} & yes & 52 & 26 \\
\hline & no & 148 & 74 \\
\hline \multirow[t]{2}{*}{ History of disasters } & yes & 77 & 38.5 \\
\hline & no & 123 & 61.5 \\
\hline \multirow[t]{5}{*}{ Type of disasters } & earthquake & 56 & 28 \\
\hline & flood & 16 & 8 \\
\hline & fire & 26 & 13 \\
\hline & epidemic & 76 & 38 \\
\hline & other & 26 & 13 \\
\hline
\end{tabular}

Table 2. Descriptive indicators of the moral courage score in the studied samples

\begin{tabular}{|l|l|l|}
\hline Variable & M $^{*}$ & SD** \\
\hline Moral agency & 18.54 & 2.79 \\
\hline Multiple values & 18.15 & 2.37 \\
\hline Endurance of threats & 2.80 & 18.29 \\
\hline Going beyond compliance & 2.49 & 17.82 \\
\hline Moral goals & 2.85 & 17.99 \\
\hline
\end{tabular}

* Mean, ${ }^{* *}$ standard deviation.

There was also a significant difference in terms of maneuver and disaster participation experience $(p>0.05)$.

There was no significant relationship between age and work experience with PMC $(p>0.05)$. However, there was no significant linear relationship between COVID-19 symptoms in family, educational level, COVID-19 symptoms in PHE staff and PMC $(p>0.05)$. The results of the independent $t$-Test showed that the mean score of PMC was significantly higher in single staff than married staff $(p<0.05, t=-0.99)$.

Results of the study on the relationship between COVID-19 symptoms and the mean score of PMC indices showed that there was no significant relationship between any of the indices and having COVID-19 symptoms. Detailed results are given in Table 3. The findings of the study on the relationship between PMC and the workplace of PHE staff also showed that the going beyond compliance has a significant relationship with the workplace of staff $(p=0.00)$, but this difference was not significant for other indicators (Table 4).

\begin{tabular}{|c|c|c|c|c|c|}
\hline Variable & Symptoms of COVID-19 & $M^{*}$ & SD** & $F$ & $p$ \\
\hline \multirow[t]{2}{*}{ Moral agency } & yes & 18.18 & 2.89 & \multirow[t]{2}{*}{0.070} & \multirow[t]{2}{*}{0.40} \\
\hline & no & 18.82 & 2.34 & & \\
\hline \multirow[t]{2}{*}{ Multiple values } & yes & 17.31 & 2.73 & \multirow[t]{2}{*}{1.02} & \multirow[t]{2}{*}{0.312} \\
\hline & no & 18.82 & 6.16 & & \\
\hline \multirow[t]{2}{*}{ Endurance of threats } & yes & 17.74 & 2.68 & \multirow[t]{2}{*}{2.12} & \multirow[t]{2}{*}{0.138} \\
\hline & no & 18.73 & 7.51 & & \\
\hline \multirow[t]{2}{*}{ Going beyond compliance } & yes & 17.71 & 2.91 & \multirow[t]{2}{*}{1.42} & \multirow[t]{2}{*}{0.23} \\
\hline & no & 17.90 & 3.03 & & \\
\hline \multirow[t]{2}{*}{ Moral goals } & yes & 17.66 & 2.85 & \multirow[t]{2}{*}{0.110} & \multirow[t]{2}{*}{0.741} \\
\hline & no & 18.24 & 2.96 & & \\
\hline
\end{tabular}

* Mean, ** standard deviation.

Table 4. Determining the relationship between the score of moral courage indicators and the workplace in the studied samples

\begin{tabular}{|c|c|c|c|c|c|}
\hline Variable & Workplace & $\mathrm{M}^{*}$ & SD** & $F$ & $p$ \\
\hline \multirow[t]{2}{*}{ Moral agency } & urban emergency care unit & 18.42 & 2.53 & \multirow[t]{2}{*}{-0.60} & \multirow[t]{2}{*}{0.93} \\
\hline & road emergency care unit & 18.64 & 2.70 & & \\
\hline \multirow[t]{2}{*}{ Multiple values } & urban emergency care unit & 17.88 & 2.77 & \multirow[t]{2}{*}{-0.69} & \multirow[t]{2}{*}{0.54} \\
\hline & road emergency care unit & 18.37 & 6.25 & & \\
\hline \multirow[t]{2}{*}{ Endurance of threats } & urban emergency care unit & 17.96 & 2.60 & \multirow[t]{2}{*}{-0.74} & \multirow[t]{2}{*}{0.23} \\
\hline & road emergency care unit & 18.57 & 7.58 & & \\
\hline \multirow[t]{2}{*}{ Going beyond compliance } & urban emergency care unit & 18.21 & 2.62 & \multirow[t]{2}{*}{1.72} & \multirow[t]{2}{*}{0.00} \\
\hline & road emergency care unit & 17.49 & 3.22 & & \\
\hline \multirow[t]{2}{*}{ Moral goals } & urban emergency care unit & 17.86 & 2.71 & \multirow[t]{2}{*}{-0.56} & \multirow[t]{2}{*}{0.63} \\
\hline & road emergency care unit & 18.09 & 3.10 & & \\
\hline
\end{tabular}

* Mean, ${ }^{* *}$ standard deviation. 


\section{Discussion}

The results of the above study showed that PHE staff had the desired and high level of PMC during the outbreak of COVID-19. Regarding the study of the PMC of medical staff in Iran and abroad, most studies have been carried out on nurses, and in the research by the authors, no study was found on the PMC of PHE staff during the outbreak of COVID-19. For example, in the study of Khajevandi et al. on the nurses of Baqiyatallah Hospital, the results showed a high level of PMC in the under-study sample [25], but Day, in his study, reported a low level of PMC in healthcare settings [26]. In the study carried out on nurses of Kashan University of Medical Sciences, Taghadosi et al. found that the average PMC of nurses was low [27], but the study of Hanifi et al. on nursing students showed the desired level of PMC [28]. Regarding the study of variables affecting the PMC of PHE staff during the COVID-19 pandemic, the results showed that there was no significant relationship between the level of education and the level of PMC of personnel.

Nejadshafiee et al., in 2020, report that there was no significant relation between education level and the ethical competency of nurses in disaster response [29], but in a study on EMS and hospital nurses, Aliakbari et al. concluded that the mean score of the nurses' ethical competencies was significantly higher in nurses with a master's degrees than in nurses with a bachelor's degrees $(p<0.01)$ [30].

In the current study, the overall score of courage in single people was higher than married people. Safarpour et al. argued that there is no significant correlation between moral courage and marital status, but a significant correlation was found between gender and moral distress. Women had more moral distress than men [31]. Some studies indicated that gender differences affect the level of people's awareness of ethical principles [32]. However, these results contradict those of some other studies. The results of a study by Aminizadeh et al. indicated that moral courage was higher in married nurses, as they have experience in coping with life's stresses, so they are better able to manage psychological stress [33].

The study results show that the going beyond compliance in city personnel was higher than staff working in road emergency. In contrast, Abadi et al. found no significant relationship between moral courage and work place [34]. Based on these contradictory results, nurses and EMS in administrative departments usually are older than staff working in road emergency, so they have greater clinical experience and are in different moral standings, which may lead to their increased their moral courage.

The results also showed a relationship between the variable of employment status and the level of courage of nurses and that formal employment nurses had more courage than contract nurses. Perhaps the level of organizational support and job security of employees can be considered an important factor in this regard. In the study by Sadooghiasl et al., in 2018, participants also stated that their work environment had a significant impact on their performance and could affect their ability and willingness to adhere to ethical principles [35]. The results of a recent study showed the direct impact of disaster-related training history and participation in maneuvers and one's presence in critical situations with the level of PMC and that people with more experience had higher PMC. In this regard, Ghaedamini et al. reported in their study that there is a direct and significant relationship between the level of moral competence of nurses to participate in a disaster and the history of one's presence in disaster exercises and drills [36].
The results of the study on the relationship between age and work experience with the mean score of PMC indicators showed no significant relationship between the overall score of PMC and work experience, but there was a statistically significant relationship between the level of courage of the samples and age. Hanifi et al. stated in his study that there was no significant relationship between age and level of PMC [28], but the results of Moosavi and Izadi showed an increase in PMC with age, which is consistent with the results in this study [37].

High levels of tension and stress in the workplace were also factors affecting the level of PMC of the studied samples. The results of studies by Abbaszadeh et al. and Jalali et al. also showed high levels of tension and moral stress in the emergency and hospital wards, which has been considered as a factor affecting the level of courage and operation of personnel [38, 39], but Fernandez-Parsons et al. stated that the level of moral stress and tension in the emergency wards was low, which is contrary to the results in this study [40]. In 2017, Aminizadeh et al. examined the relationship between nurses' PMC and moral stress in intensive care units. In this study, 310 nurses from special wards of educational hospitals in Kerman were studied. The results of this study showed that there was a significant and negative relationship between PMC and the moral stress of nurses and that strengthening PMC reduces moral stress and will increase the quality of patient care [33]. In 2014, Mahdaviseresht et al. examined the correlation between PMC and the moral sensitivity of nurses in selected medical hospitals in Tabriz. In this study, 260 nurses were selected by random sampling. The results showed that PMC has a statistically positive correlation with moral sensitivity. Raising the level of nurses' awareness of moral principles and increasing moral sensitivity brought about the development of courageous moral behaviors in nurses [41].

Safarpour et al., in thier study, stated that PMC is an important factor in reducing moral stress in the face of moral challenges, and strengthening PMC can reduce the amount of moral stress [31]. Therefore, it can be concluded that considering the high level of stress and ethical challenges of PHE staff, by using adaptive methods and training, one can help PHE staff to cope with moral stress in critical situations, such as the outbreak of COVID-19, and to be able to experience less moral stress by using these strategies. Familiarity with ethical codes can also be effective in reducing stress and being able to face ethical challenges more easily during an epidemic.

\section{Conclusions}

The findings in this study showed a significant relationship between many variables, such as moral stress, age, participation in training courses and the level of preparedness to deal with critical situations, with the level of PMC in PHE staff. Given that all PHE staff in their working conditions, and especially during the epidemic of COVID-19, are facing many stresses and moral challenges, more attention to PMC and its components is essential for them. By teaching effective coping mechanisms and reducing moral stress, effective measures can be taken to increase the PMC of PHE staff.

Acknowledgements. This study is related to a research design which was ratified and financially supported by the research and technology deputy of the Medical Sciences University of Shahrekord (Grant No. 5407). We hereby express our deep gratitude toward the respectable Deputy of Research and Technology of Shahrekord University of Medical Sciences, as well as all the participants that assisted us in this research work, without whom the study would not have be possible. 


\section{References}

1. Patterson PD, Suffoletto BP, Kupas DF, et al. Sleep quality and fatigue among prehospital providers. Prehospital Emerg Care 2010; 14(2): 187-193.

2. Patterson PD, Huang DT, Fairbanks RJ, et al. Variation in emergency medical services workplace safety culture. Prehospital Emerg Care 2010; 14(4): 448-460.

3. Soloukdar A, Goodarzi B. The Relationship of agility of human resources on performance of staffs at Tehran Emergency Center. Nurse Physician War 2019; 7(22): 27-33.

4. Ezati P, Vaziri M, Adli F. Educational needs assessment in the medical emergency technicians of Tehran emergency center. J Safety Promot Injury Prev 2017; 5(2): 109-119.

5. Bahadori M, Nasiripur A, Tofighi S, et al. Emergency medical services in Iran: an overview. Aust Med J 2010; 3(6): 335-339.

6. Bahrami M, Aliakbari F, Aein F. Iranian nurses' perception of essential competences in disaster response: a qualitative study. J Edu Health Promot 2014; 3: 81.

7. Kapucu N, Garayev V. Collaborative decision-making in emergency and disaster management. Int J Public Admin 2011; 34(6): 366-375.

8. Vegian CFL, Monteiro MI. Living and working conditions of the professionals of the a Mobile Emergency Service. Rev Lat-Am Enferm 2011; 19(4): 1018-1024.

9. Grunwald JA, Bearman C. Identifying and resolving coordinated decision making breakdowns in emergency management. Int J Emerg Manage 2017; 13(1): 68-86.

10. Reed MJ, Graham CA. Why emergency medicine needs senior decision makers. Euro J Emerg Med 2011; 18(3): 131-132.

11. Gostin LO, Friedman EA, Wetter SA. Responding to COVID-19: how to navigate a public health emergency legally and ethically. Hastings Cent Rep 2020; 50(2): 8-12.

12. Unruh JA. Moral distress: a living nightmare. J Emerg Nurs 2010; 36(3): 253-255.

13. Thorup $\mathrm{CB}$, Rundqvist $\mathrm{E}$, Roberts $\mathrm{C}$, et al. Care as a matter of courage: vulnerability, suffering and ethical formation in nursing care. Scan J Caring Sci 2012; 26(3): 427-435.

14. Dinç L, Gastmans C. Trust in nurse-patient relationships: a literature review. Nurs Ethics 2013; 20(5): 501-516.

15. Mirhosseini S, Dadgari A, Basirinezhad MH, et al. The proportion of death anxiety and its related factors during the COVID-19 pandemic in the Iranian population. Fam Med Prim Care Rev 2021; 23(1): 36-40.

16. Ahmadi M, Sharifi A, Dorosti S, et al. Investigation of effective climatology parameters on COVID-19 outbreak in Iran. Sci Total Environ 2020; 729: 138705.

17. Zareie B, Roshani A, Mansournia MA, et al. A model for COVID-19 prediction in Iran based on China parameters. MedRxiv 2020, doi: 10.1101/2020.03.19.20038950.

18. Holland M, Zaloga DJ, Friderici CS. COVID-19 Personal Protective Equipment (PPE) for the emergency physician. Visual J Emerg Med 2020; 19: 100740.

19. Nasrabadi AN, Shali M, Ghorbani A, et al. Challenges with healthcare workers' protection during the COVID-19 pandemic in Iran. British J Oral Maxillofacial Surg 2021; 59(3): e114-e117.

20. Memish ZA, Ahmed QA, Schlagenhauf P, et al. No time for dilemma: mass gatherings must be suspended. Lancet 2020; 395(10231): 1191.

21. Kuchar E, Karlikowska-Skwarnik M, Szenborn L, et al. Recommendations for primary healthcare doctors for the management of acute respiratory infections in children during the SARS-CoV-2 pandemic - COVID COMPASS. Fam Med Prim Care Rev 2021; 23(1): 116-124.

22. Razai MS, Doerholt K, Ladhani S, et al. Coronavirus disease 2019 (COVID-19): a guide for UK GPs. BMJ 2020; 368.

23. Sekerka LE, Bagozzi RP, Charnigo R. Facing ethical challenges in the workplace: conceptualizing and measuring professional moral courage. J Business Ethics 2009; 89(4): 565-579.

24. Khoshoei MS. Psychometric Properties of Professional Moral Courage Scale and it's measuring on the basis of demographic characteristics. Quarterly J Career Organizational Counseling 2014; 6(20): 44-58.

25. Khajevandi H, Ebadi A, Aghaiani Chavoshi A. Investigation of moral courage and its predictive factors in nurses of Baqiyatallah Hospital in 2019. IJME 2020; 13(1): 131-141.

26. Day L. Courage as a virtue necessary to good nursing practice. Am Crit Care 2007; 16(6): 613-616.

27. Taghadosi M, Nouri H, Gilasi HR, et al. Investigate the relationship between attitude and practical commitment to prayer with moral courage in nurses working in Kashan University of Medical Sciences, 2019. KAUMS J (FEYZ) 2020; 23(7): 749-755.

28. Hanifi N, Moqaddam M, Ghahremani Z. Factors related to moral courage of nursing students in Zanjan. Prev Care Nurs Midwifery J 2019; 9(1): 22-28.

29. Nejadshafiee M, Mirzaee M, Aliakbari F, et al. Hospital nurses' disaster competencies. Trauma Monthly 2020; 25(2): 89-95.

30. Aliakbari F, Ghaedamini M, Deris F, et al. relationship between nurses' decision-making style and their disaster response competencies. Disaster Med Public Health Prepared 2020: 1-6, doi: 10.1017/dmp.2020.225.

31. Safarpour $\mathrm{H}$, Ghazanfarabadi $\mathrm{M}$, Varasteh $\mathrm{S}$, et al. The association between moral distress and moral courage in nurses: a cross-sectional study in Iran. Ir J Nurs Midwifery Res 2020; 25(6): 533.

32. Borhani F, Mohammadi S, Roshanzadeh M. Moral distress and perception of futile care in intensive care nurses. J Med Ethics History Med 2015; 8: 2.

33. Aminizadeh $\mathrm{M}$, Arab M, Mehdipour R. Relationship moral courage to moral distress in nurses the intensive care unit. Ir J Med Ethics History Med 2017; 10(1): 131-40.

34. Abadi NE, Rahimzadeh M, Omidi A, et al. The relationship between moral courage and quality of work life among nursing staff in Bam hospitals. J Adv Pharm Educ Res 2020; 10(S1): 127-132.

35. Sadooghiasl A, Parvizy S, Ebadi A. Concept analysis of moral courage in nursing: a hybrid model. Nurs Ethics 2018; 25(1): 6-19.

36. Ghaedamini M, Aliakbari F, Masoudi $\mathrm{R}$, et al. The relationship between emotional intelligence and disaster nursing competence in nurses working in Shahrekord. J Clin Nurs Midwifery 2019; 7(4): 268-277.

37. Moosavi S, Izadi A. Comparison of moral courage of the nurses and nursing managers working in hospitals affiliated to Shahid Beheshti University of Medical Sciences. Med Ethics J 2017; 11(41): 17-24.

38. Abbaszadeh A, Borhani F, Kalantary S. The moral distress of nurses in health centers in the city of Bam in 1390. Med Ethics J 2011; 5(17): 119-140.

39. Jalali K, Tabari-Khomeiran R, Asgari F, et al. Moral distress and related factors among emergency department nurses. Eurasian J Emerg Med 2019; 18(1): 23-27.

40. Fernandez-Parsons R, Rodriguez L, Goyal D. Moral distress in emergency nurses. J Emerg Nurs 2013; 39(6): 547-552. 
41. Mahdaviseresht R, Atashzadeh-Shoorideh F, Borhani F. Correlation between moral sensitivity and moral courage in nurses of selected hospitals affiliated to Tabriz University of Medical Sciences in 2014. Ir J Med Ethics History Med 2015; 8(3): 27-39.

Tables: 4

Figures: 0

References: 41

Received: 11.06.2021

Reviewed: 15.06 .2021

Accepted: 10.08 .2021

Address for correspondence:

Mohammad Heidari, PhD

Community-Oriented Nursing Midwifery Research Center

Shahrekord University of Medical Sciences

Ayatollah Kashani Blvd

Postal Code: 8815713471

Shahrekord

Iran

Tel.: +98 913185-0128

E-mail: heidari@skums.ac.ir 